\title{
Proteomics in Evolutionary Ecology
}

Running title: Evolutionary dynamics in the proteome

\section{B. Baer \& A. H. Millar}

Centre for Integrative Bee Research (CIBER) and ARC Centre of Excellence in Plant Energy Biology, Bayliss Building, The University of Western Australia, 6009 Crawley, Australia

for correspondence Phone ++61 864884495

Fax ++6186488 1029

Email: boris.baer@uwa.edu.au 


\section{Abstract}

31 Evolutionary ecologists are traditionally gene-focused, as genes propagate phenotypic

32 traits across generations and mutations and recombination in the DNA generate genetic

33 diversity required for evolutionary processes. As a consequence, the inheritance of

34 changed DNA provides a molecular explanation for the functional changes associated

35 with natural selection. A direct focus on proteins on the other hand, the actual molecular

36 agents responsible for the expression of a phenotypic trait, receives far less interest from

37 ecologists and evolutionary biologists. This is partially due to the central dogma of

38 molecular biology that appears to define proteins as the 'dead-end of molecular

39 information flow' as well as technical limitations in identifying and studying proteins and

40 their diversity in the field and in many of the more exotic genera often favored in

41 ecological studies. Here we provide an overview of a newly forming field of research that

42 we refer to as 'Evolutionary Proteomics'. We point out that the origins of cellular

43 function are related to the properties of polypeptide and RNA and their interactions with

44 the environment, rather than DNA descent, and that the critical role of horizontal gene

45 transfer in evolution is more about coopting new proteins to impact cellular processes

46 than it is about modifying gene function. Furthermore, post-transcriptional and post-

47 translational processes generate a remarkable diversity of mature proteins from a single

48 gene, and the properties of these mature proteins can also influence inheritance through

49 genetic and perhaps epigenetic mechanisms. The influence of post-transcriptional

50 diversification on evolutionary processes could provide a novel mechanistic underpinning 
51 for elements of rapid, directed evolutionary changes and adaptations as observed for a

52 variety of evolutionary processes. Modern state-of the art technologies based on mass

53 spectrometry are now available to identify and quantify peptides, proteins, protein

54 modifications and protein interactions of interest with high accuracy and assess protein

55 diversity and function. Therefore, proteomic technologies can be viewed as providing

56 evolutionary biologist with exciting novel opportunities to understand very early events

57 in functional variation on cellular molecular machinery that are acting as part of

58 evolutionary processes.

60 Key words: Evolution, natural selection, sexual selection, peptide mass spectrometry,

61 protein diversity, post-translational modification, protein-protein interaction.

\section{Introduction}

66 Evolutionary theory as initially formulated by Charles Darwin [1] has become a

67 foundation for biological sciences and ranks among mankind's most important scientific

68 discoveries. The empirical support for evolutionary theory shows that traits under natural

69 selection require two characteristics that make them evolvable: variation and inheritance.

70 For evolutionary processes such as for example host-parasite / predator-prey coevolution,

71 sexual selection or ecological adaptation to occur, phenotypic variation between

72 individuals needs to be generated and maintained for a trait so that selection can

73 differentially act upon them. Furthermore, traits need to be heritable so that individuals 
74 with advantageous characteristics pass these onto the next generation and thereby change

75 their frequency within a population, resulting in fundamental biological developments

76 such as adaptation and speciation. The discovery of DNA by Watson and Crick [2] as the

77 molecule responsible for biological information storage and inheritance offered biologists

78 the possibility to develop and use a range of molecular tools such as PCR, sequencing

79 and cloning to understand the implications of Darwinian thinking at the molecular level

80 and across evolutionary timescales. Crick also formulated the central dogma for

81 molecular biology [3] (Figure 1), where heritable information is coded as genes, typically

82 DNA but sometimes RNA, from which proteins are produced via transcription and

83 translation. The central dogma presents proteins as the endpoint of information flow

84 where any changes are not translated back to RNA and DNA and thus proteins are

85 typically not considered as drivers of evolutionary processes. As a consequence of this

86 history, evolutionary biologists are predominantly gene-focused and the technical

87 opportunities to aid their study of genes and genomes have developed at breathtaking

88 speed up to the present day. The gene mutation paradigm as the key to evolution has

89 dominated modern molecular biology, there have been prominent thinkers such as Woese

90 [4-6] however who proposed RNA and translation to protein as central drivers of

91 phylogenetic relationships in the tree of life. Woese also highlighted the role of horizontal

92 gene transfer between prokaryotic cells (i.e. the swapping of DNA encoding for a whole

93 new protein in bacteria and archea, Figure 1) as more critical to great swathes of

94 evolution than point mutation of the organism's own genes $[4,5]$. Horizontal gene

95 transfer allows for rapid evolution to occur at the level of the ecosystem rather than the

96 level of the organism and the introduction of an entirely new protein agent into a cellular 
97 milieu and indeed into a protein network. The importance of horizontal gene transfer in

98 fungal evolution [7] and even in very recent examples of grains in pathogenicity of fungi

99 is well documented [8].

100

101 The full genome sequences of thousands of species are now available allowing

102 unprecedented base by base comparison of genes within and across families, genera and

103 kingdoms and increasingly more sophisticated methodologies are also available to

104 permanently or transiently manipulate gene sequence and expression to observed the

105 effects. However, while this genomics has generated solid empirical evidence for

106 evolutionary theory and provided detailed insights into evolutionary dynamics (e.g. [9]),

107 a range of more fundamental questions still remained unresolved. For example,

108 comparative genomics reveals that many genes often remain remarkably similar

109 throughout evolutionary history, providing, for example, only preliminary answers to the

110 question of why chimpanzees are chimpanzees and humans are humans based on DNA

111 sequence alone $[10,11]$. It is widely acknowledged that regulation of expression of

112 genomes is the key differentiator between mammals but it remains unclear, how

113 differences in gene expression of an identical gene pool can generate the tremendous

114 phenotypic variation observed such as for example between humans and chimpanzees

$115[10,11]$. Furthermore, dependence of molecular evolution of DNA on random mutations

116 alone resulting in the eventual appearance of a gene with superior functionality [12-14]

117 would relegate evolution to depend predominantly on chance events acted on by selective

118 forces across generations. In our view while the focus on point mutation alone is

119 weakening, the current framework pursued by many researchers still provides an 
120 unsatisfying and insufficient explanation for fast co-evolving traits such as for example

121 those under sexual selection or host-parasite co-evolution, where heritable changes in

122 phenotype can often become visible within a handful of generations [15-19].

124 The predominance of evolutionary studies still focuses on genes and genomes through

125 measures of mutation rates and genotype frequency changes in populations. There is no

126 current evolutionary framework or substantial research literature to understand the

127 importance of the role of translated agents - the proteins and their function - as drivers of

128 adaptation. This can be very simplistically illustrated by the co-occurrence of 'genome

129 and evolution' and 'proteome and evolution' in PubMed: a close to 50-fold difference in

130 co-occurrence exists. Woese [4] pointed out a similar dilemma for RNA biology a decade

131 ago where the importance of studying the evolution of translation of RNA to protein did

132 not fit within the molecular biology paradigm. As he pointed out in his seminal

133 contribution, "molecular biology has to bring evolution to the fore and integrate it fully -

134 not hold it at arm's length" [5]. Much has changed to resolve this as the explosion of data

135 on numerous levels of RNA biology and the biological role of non-translated RNAs in

136 influencing DNA [20] (Figure 1) has revealed a modern 'RNA world' in eukaryotes to

137 mirror the ancestral RNA world at the time of archea and bacteria divergence [21, 22].

139 In a similar way, we contend in this review that proteins are crucial molecules to study

140 directly when addressing the scientific questions typically investigated by evolutionary

141 biologists for a variety of reasons. First they normally represent the functional units ("the

142 agents") at the molecular level that are directly responsible for a phenotype seen on the 
143 macroscopic scale. Secondly, most environmental factors, that are not direct mutagens,

144 act firstly on proteins and only secondarily on the genome. Thirdly, proteins are

145 responsible for determining transcriptional competency of significant portions of a given

146 genome by controlling eu/heterochromatin modulation and thus access of the

147 transcription machinery (Figure 1). This becomes increasingly more important given that

148 work over the last two decades has revealed that genes can produce a substantial variety

149 of proteins with fundamentally differed functions through both post-transcriptional

150 processing and post-translational modifications [23]. The idea of post-translational

151 marking as a driver of protein-protein interaction and of this marking as a "protein

152 interaction code' has been proposed based on a range of examples in yeast [24]. Thirdly,

153 the state and function of a specific protein is influenced by both the proteome as a whole

154 and the influence of the prevailing environment. Fourthly, proteins are the agents for

155 epigenetic marking of genomes through histone modification and DNA methylation [25-

156 27] (Figure 1), and hence the proteome has the potential for trans-generational influence

157 both as the end product of the genome and also as epigenome modifying agents. Fifthly,

158 and as pointed out by several recent reviews [28-31], advances in protein biochemistry

159 now allow the assessment of the abundance, location, modification and function of

160 proteins, from isolated single proteins to complex mixtures from whole tissue extracts

$161[32,33]$. Proteomic technologies therefore provide capacity for the study of biological

162 mixtures of proteins and the use of a range of separation techniques from gel

163 electrophoresis to liquid chromatography coupled to different types of mass spectrometry

164 to analyze, quantify and identify differences in the proteome $[28,34,35]$. Separations in

165 gel, in liquid media and on solid surfaces provide physical arrays of proteins for 
166 comparison of differences samples. Peptide mass spectrometry allows the pattern

167 matching based identification of peptides to track them back to all the specific genome

168 loci that encode them [36]. Increasing, the techniques of proteomics also allow the

169 assessment of smaller samples, faster and more accurately, and population level analysis

170 of individuals is already a reality [37]. Mass spectrometry can identify and quantify not

171 only the abundance of proteins, but also many modifications to proteins induced by

172 ecological stimuli and through genetic susceptibility to modification [32]. Changes in the

173 partnering and strength of protein-protein interactions will also soon be able to be

174 predicted, detected and quantified [38].

176 If we consequently consider protein synthesis and maturation as quantifiable mechanisms

177 to produce natural variation in gene products that selection can act upon and that can be

178 inherited, we need to integrate the analysis of proteins and their functions into a larger

179 framework for evolutionary biology using readily available molecular systems biology

180 approaches (see Table 1 for some examples). In our view this generates very exciting

181 opportunities for future research. There are a number of textbook examples where

182 proteins are involved in dynamics of evolutionary importance. For example trans-

183 generational movement of antibodies initiating immune competence from mother to child

184 [39], or Darwinian evolution of prion proteins in response to host competition [40]. But

185 what we will discuss in more detail here is that proteins more generally have an

186 underlying and fundamental role in phenotypic variation that is acted upon by evolution

187 across all species and considerable work is required to build and understand the

188 mechanisms that underpin it. 
190 To build a strong framework of connection between proteomics and evolutionary theory

191 we start with a general and understandable introduction into protein dynamics and protein

192 networks and then consider the proteomic technologies and their possibilities and

193 limitations for use by evolutionary biologists (Table1). To exemplify some of the

194 theoretical considerations we then provide our own experience in attempting to bridge

195 these worlds through work on reproductive processes and pathogen susceptibility in two

196 model insects - the honeybee Apis mellifera and the leaf cutter ant Atta colombica. In the

197 later paragraphs we point out the major questions and challenges that remain to be

198 studied. Our main aim in writing this paper is to encourage biologists of all fields to

199 consider recent advances in understanding of proteins and the broader field of proteomics

200 for their future work on evolutionary questions.

\section{Proteins are more diverse than the genes that encode them}

205 The primary structure of a protein is a string with each position occupied by one of 23

206 different amino acids. Each is decoded from defined sets of triplet bases containing one,

207 two or three of the four bases of DNA. As macromolecules, proteins have a huge range of

208 size, complexity and a much wider range of physical properties than the DNA that

209 encodes them. Individual proteins can interact with substrates and products in catalysis,

210 or with structural partner proteins through surface residue interactions. Different proteins

211 can operate in aqueous or highly hydrophobic environments and in a temperature range of 
212 over $120^{\circ} \mathrm{C}$, from less than $-20^{\circ} \mathrm{C}$ in arctic and alpine species to more than $100^{\circ} \mathrm{C}$ in

213 species within volcanic vents [41, 42]. It is widely presumed by evolutionary biologists

214 that proteins have little plasticity of function, no memory and very limited ability to adapt

215 to changing molecular environments. However, protein biochemistry shows this is not

216 really the case [43]. The functioning of proteins can generate alterations of their native

217 conformation that can impact their future function. Proteins can also have their kinetic

218 characteristics altered by external stimuli, thereby changing the way they interact with

219 substrates and products. This can occur through covalent modification of amino acids by

220 processes including phosphorylation, acetylation or glycosylation [24], or reversibly by

221 allosteric activation or inhibition through the binding to proteins of small molecules other

222 than substrates or products [44].

\section{Proteins are organized in networks and groups of networks}

225 Complex phenotypic traits are not caused by a single protein but are usually the result of

226 an organized co-occurrence of a set of proteins (Figure 1). Collectively such sets of

227 proteins constitute functional networks with further aspects of flexibility. A protein

228 network can have nodes and hubs, multiple inputs and outputs, and can operate at

229 different states of flux depending on the starting conditions. One new enzyme added to

230 the network can even reorganize the node-wiring diagram, bridge between pathways and

231 thus impact the network flux more dramatically than its individual role as a single

232 protein. Horizontal gene transfer is a means of introduction of new protein players into

233 networks from other organisms in an ecosystem (Figure 1) [4, 6], and a raft of insights

234 into the post-translational evolutionary processes regulating protein abundance have 
235 recently been reviewed [45]. The complexity of such networks is further increased

236 because proteins often have multiple functions and can therefore be found in multiple

237 proteomic networks, providing links and possibilities for interactions between them.

239 The presence of complex proteomic networks underlying macroscopically observed

240 phenomena has several potential consequences: The different subtasks of networks are at 241 risk of interfering with each other, both at the level of the proteins themselves and at the

242 level of the metabolic pools that interconnect them. For example, proteases involved in

243 host-parasite interactions can damage other proteins both in the host and parasite [46, 47],

244 while enzymes producing free radical species can cause oxidation of other proteins

245 through their reactive products [48]. Consequently we might expect evolutionary trade-

246 offs to be apparent within protein networks and the ways network components can evolve

247 is likely to be more restricted for those components that fulfill core functions in each

248 network. This means the evolutionary clock will tick at different speeds for the

249 corresponding genes coding for these proteins within a given network, depending on the

250 biological activity of proteins or subgroups of proteins and their degree of connectivity to

251 functional networks. Interestingly the high frequency of selection of functional

252 modifications in metabolic enzyme loci associated with the TCA cycle and glycolysis and 253 their secondary roles in cells has already been highlighted [49]. 
258 A problem we face is how best to describe the functioning as well as the evolvability of

259 protein networks in a way that can illustrate the action of selective processes.

260 Mathematicians use matrices to define the condition of an N-dimensional structure. By

261 the same analogy we can describe a proteomic network as an N-dimensional matrix

262 where each individual protein or pathway represents an additional dimension (vector)

263 within the matrix and values within the matrix define individual network characteristics

264 such as metabolic flux. The matrix is initially defined by genotype, but after its

265 formation, it's phenotypic expression can be represented in several different ways and

266 powerfully influenced the interaction of its components:

268 Firstly, a protein matrix can be seen as information processing machinery. Input variables

269 (an input vector that consists of internal or environmental stimuli) are entered into the

270 matrix and ultimately produce a response variable with a phenotypic expression on the

271 cellular or individual level. The stimulus could be a protein or a metabolite (or several or

272 a combination) that enters a biochemical network and finally generates a product that has

273 biological activity; for example, a neurotransmitter to influence development, or a

274 metabolic substrate or antioxidant to nurture or defend a cell or tissue.

276 Secondly, a protein matrix can be seen as an information storage device. In such a case

277 the input variables can be seen as a matrix as well and the interaction of matrices produce

278 a new but altered one. This change, dilution or modification will affect the possible

279 output from what has been mentioned above. These modified functions can be "stored"

280 within the matrix in a short time frame. For example proteins within networks could be 
281 degraded by proteases or post-translationally modified or allosterically activated or

282 inhibited, and thereby biochemical pathways blocked or metabolic flows diverged that

283 would normally have been expected as physiological responses. Multiple modifications at

284 closely arranged sites can ultimately represent logic functions, building logic gates that

285 can impact the protein network function [32].

\section{Evolutionary dynamics of protein network matrices}

289 Our discussion about protein networks and selection acting on them as presented in the

290 last chapters also allows us to propose elements of a continuum, starting from instant

291 physiological effects influencing a trait under selection right through to the

292 transgenerational dynamics that evolutionary ecologists typically investigate in their

293 macroscopic trait studies. However, for biochemical credibility, such a pathway needs

294 definable and measureable components that underpin mechanisms. In our view, many of

295 the elements needed are already known and simply need to be placed within a connected

296 framework of evolutionary biology as outlined below.

298 A protein matrix is able to respond to its environment rapidly in seconds to minutes, such

299 as for example the detection of the presence of a pathogen. This produces a matrix output

300 that selection can operate on in minutes; for example, an oxygen radical is detoxified by

301 antioxidant machinery, or alternatively it damages a protein altering the flux through a

302 metabolic pathway, or a protein in phosphorylated changing its function or interaction

303 partners. The manipulation of the protein matrix then moves it into a new equilibrium or 
304 phenotype with altered attributes over a period of hours; for example changes in

305 metabolic pools which can then feedback or feed forward on gene expression providing

306 new components to the matrix. Prolonged changes in gene expression will alter the

307 proteome, but can also influence both the mRNA pool and the smallRNA and miRNA

308 pools. Through mechanisms such as RNA-directed DNA methylation or alterations of

309 histone modification in regions of active transcription, over days to months, these altered

310 gene expression changes can modify epigenetic marks on the DNA leading to altered

311 epigenetic states of specific cells. Methylation patterning and corresponding changes in

312 histone binding and modification can in some cases be heritable, providing a

313 transgenerational flow of protein matrix attributes. There is also a further stage of this

314 process, as there is now clear evidence that methylated regions of DNA have higher

315 mutation rates [50] due to spontaneous deamination of methyl-cytosine and subsequent

316 mismatching during DNA duplication to replace a CG couple with an AT couple,

317 yielding a single nucleotide polymorphism. Hence changes to proteome matrices that can

318 feedback to gene expression have the potential to influence the evolution of genes that

319 influence them in a targeted fashion. Examples of the role of post-translational

320 modification processes [51] and of DNA methylation $[52,53]$ in evolutionary processes

321 have been reviewed.

\section{Evolutionary biology from a protein perspective:}

325 The ideas and hypotheses raised so far in this paper originate from the literature that has

326 combined protein biochemistry with evolutionary ecology. Such empirical cross 
327 disciplinary work conducted over the last decade provides a number of interesting

328 examples of how questions derived from evolutionary biology have been approached

329 using a combination of discovery based proteomic analyses and the typical, hypotheses

330 driven approaches used in evolutionary ecology (see Table 1 for more details and

331 examples). For example, proteins have been shown to be phenotypically plastic, if they

332 lack a defined stable secondary or tertiary structure [54]. Regions within proteins that

333 show such plasticity play a key role in protein-protein interaction networks, which might

334 provide functional advantages. Because of their higher capacity to rewire with other

335 protein partners, they also seem to evolve rapidly [54]. Proteomics has also been used in

336 phylogenetic studies to understand the evolution of traits of interest, for example key

337 physiological traits such as protein translation throughout the tree of life [55]. Proteomic

338 approaches revealed how individual proteins such as Hsp90 can impact developmental

339 networks and thereby influence morphological phenotypes and their evolution [56]. An

340 interesting example of protein based inheritance has recently been reported in the

341 honeybee Apis mellifera, where the egg yolk protein vitellogenin can bind to a bacterial

342 bee pathogen and is used as a carrier of microbial fragments to eggs, resulting in immune

343 priming of offspring [57].

345 Sexual reproduction typically involves behavioral interactions by two or more individuals

346 on the macroscopic level but numerous key processes are occurring at the level of

347 proteins [58]. These interactions are typically characterized by the presence of strong

348 selective forces acting on individual fitness and by fast evolutionary change. Males have

349 to provide females with sufficient numbers of viable sperm but often compete against 
350 each other within the females' sexual tract for access to eggs. Consequently, evolutionary

351 ecologists had a long standing interest to untangle those traits that support the cooperative

352 aspects of sexual reproduction from those responsible for the conflicts over paternity and

353 understand their impact and male and female reproductive success. Proteomics has

354 already been used in a wide range of different organisms to identify male reproductive

355 proteins, which provided key insights into the make up of ejaculates [59-70] and

356 triggered studies to unravel their effects on females and reproductive success [69, 71-75].

357 The identification of these proteins and a more detailed understanding about their

358 function has enabled comparative studies to investigate the evolutionary history and

359 phylogenetic relationships for some of these proteins [76-78].

361 In the next section we will further elaborate on such reproductive proteomics by

362 summarizing our own findings, which offers us an opportunity to discuss our strategy and

363 intent behind our scientific progress. Furthermore, commentary on the timeline of

364 discovery and our unpublished and pilot data allows us to provide a more general

365 overview of the benefits of proteomics for evolutionary research. Proteomics was without

366 doubt the key tool we used over the last 10 years to gain major insights into highly

367 complex biological processes and to begin to hone in on proximate mechanisms that

368 underlie reproductive traits such as high quality sperm and long-term sperm storage. We

369 started with the identification of lists of proteins in samples of interest. While this is often

370 flagged as a limitation of proteomics, because it cannot provide causal relationships, it

371 provided our protein landscape for the following years. As we illustrate below in detail,

372 these parts lists guided consequently phenotypic studies providing not only answers to 
373 our initial questions but a substantially broader and systemic insight into the molecular

374 function of social insect reproduction.

376 An example from our own research on insect reproduction

378 We studied sexual reproduction in Hymenopteran social insects, being the eusocial ants,

379 bees and wasps. Their societies are characterized by the presence of a single or very few

380 reproductive animals, typically referred to as queens, and a non-reproducing cast known

381 as workers [79-82]. Workers benefit from helping if they are related to the helped

382 individual, known as inclusive fitness benefits [83, 84]. Because helping incentive

383 increases with helper relatedness, social insects queens perform only a single round of

384 mate choice and sperm acquisition and never replenish sperm once they have started to

385 lay eggs. This has resulted in the evolution of spectacular reproductive adaptations in

386 species with large and long lived societies, where males produce exceptionally large

387 ejaculates of high quality [85], and queens store them for decades to sire millions of

388 offspring $[86,87]$. Although these reproductive traits must have been key during social

389 evolution and will have contributed towards the remarkable ecological success of these

390 animals [88], the proximate mechanisms to achieve such high levels of fertility or their

391 evolution had remained completely unknown.

392 During mating males transfer ejaculates to females that consist of sperm and glandular

393 secretions known as seminal fluid, which has increasingly been recognized to contain key

394 molecules determining male and female reproductive success [89-92]. Seminal fluid can

395 also produce mating plugs or mating signs [81, 93-96], which influence the mating 
396 behavior of bumblebee queens [97, 98], providing the first evidence that seminal fluid

397 components are important in social insects.

398 With this background we started our collaborative work together by a discovery inspired

399 proteomic characterization of seminal fluid in honeybees [99], revealing a first insight

400 and basic parts map of its molecular landscape. This list of proteins proved to be of

401 significant scientific value because functional analyses predicted biological functions and

402 generated a wealth of hypothesis and ideas that consequently guided our further

403 experimental work. We found that seminal fluid proteins consisted of three major groups

404 of proteins, that (1) keep sperm alive (2) defend sperm and queens from pathogens and

405 (3) are molecular agents of sexual conflict. Follow up experimental work confirmed that

406 seminal fluid is indeed exceptionally potent in keeping sperm alive and that proteins are

407 the key molecules responsible for this effect $[100,101]$. The detection of antimicrobial

408 proteins in the seminal fluid triggered a search for pathogens in honeybee ejaculates, and

409 resulted in the identification of two widespread bee pathogens in ejaculates, Nosema apis

410 and Nosema ceranae [102, 103]. Our finding of antifungal proteins in seminal fluid

411 implied that males may be able to combat these infections in their ejaculates.

412 Experimental follow up showed that seminal fluid is indeed remarkably efficient in

413 killing N. apis spores (Peng et al., submitted). Moreover, our data revealed that the

414 pathogen is killed in at least two distinctly different ways, implying that there is

415 redundancy in the defense system of seminal fluid as well as some specificity, because

416 the biologically active molecules show no antimicrobial activity against a series of non-

417 pathogenic microbes. Both redundancy and specificity of honeybee antimicrobial proteins

418 were novel findings that had not been reported previously for insects. Thirdly, we found 
419 molecules that we predicted to be involved in sexual conflict. The presence of ejaculates

420 from multiple males within a female's sexual tract can result in postcopulatory sexual

421 selection, operating either as sperm competition [104] or cryptic female choice [105]. We

422 hypothesized that the battlegrounds of these events are extracellular spaces dominated by

423 secreted proteomes and the effective role and variability of these protein sets would be

424 defining paternity success. We indeed found that seminal fluid proteins of polyandrous

425 honeybees and leaf cutter ants are capable to kill sperm of rival males, known as sperm

426 incapacitation [106].

427 This shows how our initial identification of proteins in the seminal fluid of honeybees

428 generated a number of predictions about function, which were accurate because we were

429 able to confirm the expected phenotypes through follow up experiments. The proteins

430 identified were confirmed to be the biologically active molecules, and our functional

431 analyses have already provided subsets of target proteins for further study [107]. Finally,

432 our work indicated that seminal fluid proteins or protein networks interact with other

433 proteomes, such as those of rival ejaculates, the queen or parasites, encouraging us to also

434 identify these additional proteomes.

435 The honeybee sperm proteome revealed the presence of a very distinct subset of proteins

436 [108], many of them being related to energy metabolism. Their high abundance in

437 honeybee sperm implied that the survival of high quality sperm is closely associated with

438 energy production. When we quantified the effect of some of these proteins on sperm

439 metabolism we were able to confirm that these proteins are biologically active and are

440 key for sperm survival. A second group of abundant proteins we detected in honeybee

441 sperm are related to transcriptional or translational activities, which was surprising given 
442 that sperm is often believed to be translationally and transcriptionally silent. Providing

443 sperm with radiolabeled amino acids confirmed that sperm indeed produce proteins at a

444 low rate [109].

446 As well as producing high quality sperm, social insects are also the 'world record

447 holders' for storing sperm [81, 86, 87]. To achieve this, queens provide sperm with

448 spermathecal fluid, a glandular secretion continuously added to sperm during storage.

449 The proteomic profiles of spermathecal fluid was distinct from that of seminal fluid [110]

450 indicating that sperm are able to survive in two very different biochemical environments.

451 The seminal fluid proteome forms a loosely connected network of proteins, consistent

452 with the expectation that these proteins are responsible for more individual tasks such as

453 keeping sperm alive, killing rival sperm and parasites or manipulating female physiology

$454[100,101,106,110,111]$. The spermathecal proteome on the other hand keeps sperm

455 alive for years, and its high connectivity seems to provide a biochemical environment that

456 has been selected for maximized sperm survival [110]. We therefore expected the

457 proteome of sperm to adapt to these changes in their biochemical environment. We have

458 now confirmed this experimentally [107], and key enzymes with changed abundances

459 were as expected related to energy production. Consequently, we were able to provide

460 important molecular insights into the secrets of long-term sperm storage, which were

461 facilitated by the presence of a relatively small number of enzymes that maximize ATP

462 production and minimize oxidative stress.

463

464 Apart from the proteome differences between stored and ejaculated sperm we have also 
465 found other proteomes to be remarkably plastic, for example between seminal fluid

466 samples from males of different bee lineages [111] or between seminal fluid of infected

467 and uninfected males (Grassl et al in preparation). These studies reveal that the

468 proteomes of ejaculates provide a useful model system to understand proteomic networks

469 and their functioning in an evolutionary framework, because the proteomes investigated

470 are substantially smaller than those of entire cells, organs or organisms, and the strong

471 selective forces or ecological stimuli that impact them result in fast changes in these

472 secreted proteomes and functional changes in proteomic networks that can be measured

473 in vitro. These studies merely mark a starting point and demonstrate the feasibility of

474 fruitful collaborations between proteomics and evolutionary biology researchers - what

475 we plan now are studies that quantify the phenotypic variation of proteomes and to

476 quantify their hypothesized heritability. Furthermore, the identification of individual

477 proteins or protein networks of interest now allow us to also conduct phylogenetic

478 comparisons to understand the evolutionary history of proteins and the way underlying

479 proteomic networks co-evolved with traits of interest, similar to what has been done in

480 other species [77].

481 Our work on evolutionary proteomics revealed that proteomic investigations tend to take

482 substantially longer to conduct and publish, as they generate larger datasets that require

483 substantially more time to analyze than classical studies typically conducted in behavioral

484 ecology. However, such detailed data mining resulted in the development of predictions

485 and hypotheses and the accuracy of these predictions was found, in time, to be highly

486 consistent with the mechanisms uncovered. Consequently, proteomics can also be used as

487 a highly efficient and accurate tool for the development and formulation of testable 
hypotheses.

\section{The future of evolutionary proteomics}

492

493 Developing a framework for how proteins play an important role for evolutionary

494 processes is critical for engagement of researchers with expertise in each area.

495 Biochemical approaches to identify and study proteins and their abundance and

496 functionality have been rapidly developing over the last decade and are now much more

497 easily accessible for a wider range of scientists including evolutionary biologists [30, 31,

498 112]. Academic institutions as well as private companies offer collaborations and

499 services to analyze protein samples of interest. With this technical feasibility, proteomes

500 can be studied in an evolutionary framework that does not differ in any major way from

501 any other phenotypic trait of interest studied by evolutionary biologists over the last 150

502 years. What is still needed are larger scale experimental studies quantifying natural

503 variation in protein profiles within and between individuals of the same and different

504 populations in order to understand how much of the theoretically achievable variation in

505 proteomes is actually realized and selected for. Furthermore we need a better

506 understanding of how the interactions between environmental factors and an individual's

507 proteome operate, both in the short as well as in the long term. Such studies will provide

508 crucial insights into an individual's opportunity to actively respond and adapt to changing

509 environments and can test for the degree of heritability of modified proteomic networks

510 characteristics. Finally, studies are needed that quantify the overall effect of proteins on

511 evolutionary processes in order to understand whether they are only important for a 
512 subset of processes such as sperm competition and immunity or whether they are in fact

513 additional drivers of evolution more generally.

\section{Summary}

517 The traditional split between biological sciences focused on either proximate or ultimate

518 questions is starting to diminish. One of the reasons for this is that molecular insights into

519 how life works have exponentially grown over the last decade, due in significant measure

520 to spectacular technological breakthroughs that now allow the study of molecular

521 dynamics in cells and entire organisms and even their extrapolation to wider habitats and

522 ecosystems. Genomics has provided evolutionary biologists with new and exciting

523 opportunities to understand and investigate evolutionary concepts. The rapidly evolving

524 field of proteomics now needs researchers with evolutionary questions to link protein

525 networks and their functioning to complex organismic characteristics.

\section{Acknowledgements}

529 We were supported by the Australian Research Council (ARC) through a Queen

530 Elizabeth II Fellowship and a Future Fellowship to BB, a Future Fellowship to AHM, an

531 ARC Linkage Project to BB and the facilities of the ARC Centre of Excellence in Plant

532 Energy Biology. We thank Barbara Baer-Imhoof, Koos Boomsma, Julia Grassl and

533 Susanne den Boer for continuous discussions and feedback, which was important to

534 develop and write this review. 


\section{References}

[1] Darwin C. The origin of species by means of natural selection. London: John Murray;

5401859.

541 [2] Watson JD, Crick FHC. Molecular structure of nucelic acids - a structure for

542 deoxyribose nucleic acid. Nature. 1953;171:737-8.

543 [3] Crick F. Central dogma of molecular biology. Nature. 1970;227:561-\&.

544 [4] Woese CR. On the evolution of cells. Proc Natl Acad Sci U S A. 2002;99:8742-7.

545 [5] Woese CR. Translation: In retrospect and prospect. RNA. 2001;7:1055-67.

546 [6] Koonin EV. Carl Woese's vision of cellular evolution and the domains of life. RNA

547 Biol. 2014;11:197-204.

548 [7] Gladieux P, Ropars J, Badouin H, Branca A, Aguileta G, De Vienne DM, et al.

549 Fungal evolutionary genomics provides insight into the mechanisms of adaptive

550 divergence in eukaryotes. Mol Ecol. 2014;23:753-73.

551 [8] Oliver RP, Friesen TL, Faris JD, Solomon PS. Stagonospora nodorum: From

552 pathology to genomics and host resistance. Annu Rev Phytopathol. 2012;50:23-43.

553 [9] Seehausen O, Butlin RK, Keller I, Wagner CE, Boughman JW, Hohenlohe PA, et al.

554 Genomics and the origin of species. Nat Rev Genet. 2014;15:176-92.

555 [10] Varki A, Nelson DL. Genomic comparisons of humans and chimpanzees. Annu Rev

556 Anthropol. 2007;36:191-209.

557 [11] Prado-Martinez J, Sudmant PH, Kidd JM, Li H, Kelley JL, Lorente-Galdos B, et al.

558 Great ape genetic diversity and population history. Nature. 2013;499:471-5.

559 [12] Przeworski M, Coop G, Wall JD. The signature of positive selection on standing

560 genetic variation. Evolution. 2005;59:2312-23.

561 [13] Vitti JJ, Grossman SR, Sabeti PC. Detecting natural selection in genomic data. Annu

562 Rev Genet. 2013;47:97-120.

563 [14] Meyer RS, Purugganan MD. Evolution of crop species: genetics of domestication

564 and diversification. Nat Rev Genet. 2013;14:840-52.

565 [15] Ebert D. Experimental evolution of parasites. Science. 1998;282:1432-5.

566 [16] Firman RC, Garcia-Gonzalez F, Thyer E, Wheeler S, Yamin Z, Yuan M, et al.

567 Evolutionary change in testes tissue composition among experimental populations of

568 house mice. Evolution. 2015;69:848-55.

569 [17] Firman RC, Simmons LW. Experimental evolution of sperm competitiveness in a

570 mammal. BMC Evol Biol Bmc Evolutionary Biology. 2011;11.

571 [18] Snook RR, Robertson A, Crudgington HS, Ritchie MG. Experimental manipulation

572 of sexual selection and the evolution of courtship song in Drosophila pseudoobscura.

573 Behav Genet. 2005;35:245-55.

574 [19] Snook RR. Sexual selection: Conflict, kindness and chicanery. Curr Biol.

575 2001;11:R337-R41. 
576

577

578

579

580

581

582

583

584

585

586

587

588

589

590

591

592

593

594

595

596

597

598

599

600

601

602

603

604

605

606

607

608

609

610

611

612

613

614

615

616

617

618

619

620

[20] Krishnan J, Mishra RK. Emerging trends of long non-coding RNAs in gene activation. Febs J. 2014;281:34-45.

[21] Groen JN, Capraro D, Morris KV. The emerging role of pseudogene expressed noncoding RNAs in cellular functions. Int J Biochem Cell Biol. 2014;54:350-5.

[22] Chen YN, Xiong XD. Long noncoding RNA and epigenetic regulation. Prog Biochem Biophys. 2014;41:723-30.

[23] Black DL. Mechanisms of alternative pre-messenger RNA splicing. Annu Rev Biochem. 2003;72:291-336.

[24] Winter DL, Erce MA, Wilkins MR. A web of possibilities: network-based discovery of protein interaction codes. Journal of Proteome Research. 2014;13:5333-8.

[25] Jaenisch R, Bird A. Epigenetic regulation of gene expression: how the genome integrates intrinsic and environmental signals. Nature Genetics. 2003;33:245-54.

[26] Jones PA. Functions of DNA methylation: islands, start sites, gene bodies and beyond. Nat Rev Genet. 2012;13:484-92.

[27] Maunakea AK, Nagarajan RP, Bilenky M, Ballinger TJ, D'Souza C, Fouse SD, et al. Conserved role of intragenic DNA methylation in regulating alternative promoters.

Nature. 2010;466:253-U131.

[28] Lesur A, Domon B. Advances in high-resolution accurate mass spectrometry application to targeted proteomics. Proteomics. 2015;15:880-90.

[29] Boersema PJ, Kahraman A, Picotti P. Proteomics beyond large-scale protein expression analysis. Curr Opin Biotechnol 2015;34:162-70.

[30] Karr TL. Application of proteomics to ecology and population biology. Heredity. 2008;100:200-6.

[31] Diz AP, Martinez-Fernandez M, Rolan-Alvarez E. Proteomics in evolutionary ecology: linking the genotype with the phenotype. Mol Ecol. 2012;21:1060-80.

[32] Maarten Altelaar AF, Munoz J, Heck AJR. Next-generation proteomics: towards an integrative view of proteome dynamics. Nature Rev Gen 2013;14:35-48.

[33] LaCava J, Molloy KR, Taylor MS, Domanski M, Chait BT, Rout MP. Affinity proteomics to study endogenous protein complexes: pointers, pitfalls, preferences and perspectives. Biotechniques. 2015;58:103-19.

[34] Christoforou AL, Lilley KS. Isobaric tagging approaches in quantitative proteomics: the ups and downs. Anal Bioanal Chem. 2012;404:1029-37.

[35] Kline KG, Sussman MR. Protein quantitation using isotope-assisted mass spectrometry. Annu Rev Biophys. 2010;39:291-308.

[36] Breker M, Schuldiner M. The emergence of proteome-wide technologies: systematic analysis of proteins comes of age. Rev Mol Cell Biol. 2014;7:453-64.

[37] Nedelkov D, Kiernan UA, Niederkofler EE, Tubbs KA, Nelson RW. Population proteomics: the concept, attributes, and potential for cancer biomarker research. Mol Cell Proteomics. 2006;5:1811-8.

[38] Kastritis PL, Bonvin AM. On the binding affinity of macromolecular interactions: daring to ask why proteins interact. J R Soc Interface. 2012;10:20120835.

[39] Carlier Y, Truyens C. Influence of maternal infection on offspring resistance towards parasites. Parasitol Today. 1995;11:94-9.

[40] Li JL, Browning S, Mahal SP, Oelschlegel AM, Weissmann C. Darwinian evolution of prions in cell culture. Science. 2010;327:869-72. 
[41] De Maayer P, Anderson D, Cary C, Cowan DA. Some like it cold: understanding the survival strategies of psychrophiles. EMBO Rep. 2014;15:508-17.

[42] Minic Z, Serre V, Herve G. Adaptation of organisms to extreme conditions of deepsea hydrothermal vents. C R Biol. 2006;329:527-40.

[43] Vuillon L, Lesieur C. From local to global changes in proteins: a network view. Curr Opin Struct Biol. 2015;31:1-8.

[44] Kokkinidis M, Glykos NM, Fadouloglou VE. Protein flexibility and enzymatic catalysis. Adv Protein Chem Struct Biol. 2012;87:181-218.

[45] Vogel C, Marcotte EM. Insights into the regulation of protein abundance from proteomic and transcriptomic analyses. Nat Rev Genet. 2012;13:227-32.

[46] Amano A, Takeuchi H, Furuta N. Outer membrane vesicles function as offensive weapons in host-parasite interactions. Microbes Infect 2010;12:791-8.

[47] Pejler G, Abrink M, Ringvall M, Wernersson S. Mast cell proteases. Adv Immunol. 2007;95:167-255.

[48] Gupta RK, Patel AK, Shah N, Choudhary AK, Jha UK, Yadav UC, et al. Oxidative stress and antioxidants in disease and cancer: A review. Asian Pac J Cancer Prev. 2014;15:4405-9.

[49] Marden JH. Nature's inordinate fondness for metabolic enzymes: why metabolic enzyme loci are so frequently targets of selection. Mol Ecol. 2013;22:5743-64.

[50] Cooper DN, Krawczak M. Cytosine methylation and the fate of CpG dinucleotides in vertebrate genomes. Hum Genet. 1989;83:181-8.

[51] Beltrao P, Bork P, Krogan NJ, van Noort V. Evolution and functional cross-talk of protein post-translational modifications. Mol Syst Biol. 2013;9.

[52] Carbone L, Harris RA, Vessere GM, Mootnick AR, Humphray S, Rogers J, et al.

Evolutionary breakpoints in the gibbon suggest association between Cytosine methylation and karyotype evolution. PLoS Genet. 2009;5.

[53] Burggren WW, Crews D. Epigenetics in comparative biology: Why we should pay attention. Integr Comp Biol. 2014;54:7-20.

[54] Mosca R, Pache RA, Aloy P. The role of structural disorder in the rewiring of protein interactions through evolution. Mol Cell Proteomics. 2012;11.

[55] Mahlab S, Linial M. Speed controls in translating secretory proteins in Eukaryotes an evolutionary perspective. PLoS Comput Biol. 2014;10.

[56] Rutherford S, Knapp JR, Csermely P. Hsp90 and developmental networks. AdvExpMedBiol. 2007;594:190-7.

[57] Salmela H, Amdam GV, Freitak D. Transfer of immunity from mother to offspring is mediated via egg-yolk protein vitellogenin. PLOS PATHOGENS. 2015;11:e1005015. [58] Birkhead TR, Hosken DJ, Pitnick S. Sperm Biology: An evolutionary perspective. Amsterdam: Elsevier; 2009.

[59] Solomon B, Duncan MW. Proteomics of seminal fluid. In: Thongboonkerd V, editor. Proteomics of human body fluids. Totowa, NJ: Humana Press Inc.; 2007. p. 467-93. [60] Takemori N, Yamamoto MT. Proteome mapping of the Drosophila melanogaster male reproductive system. Proteomics. 2009;9:2484-93.

[61] Oliva R, de Mateo S, Estanyol JM. Sperm cell proteomics. Proteomics. 2009;9:100417.

[62] Miller I, Friedlein A, Tsangaris G, Maris A, Fountoulakis M, Gemeiner M. The serum proteome of Equus caballus. Proteomics. 2004;4:3227-34. 
667

668

669

670

671

672

673

674

675

676

677

678

679

680

681

682

683

684

685

686

687

688

689

690

691

692

693

694

695

696

697

698

699

700

701

702

703

704

705

706

707

708

709

710

711

712

[63] Kelly VC, Kuy S, Palmer DJ, Xu ZZ, Davis SR, Cooper GJ. Characterization of bovine seminal plasma by proteomics. Proteomics. 2006;6:5826-33.

[64] Walker MJ, Rylett CM, Keen JN, Audsley N, Sajid M, Shirras AD, et al. Proteomic identification of Drosophila melanogaster male accessory gland proteins, including a pro-cathepsin and a soluble gamma-glutamyl transpeptidase. Proteome Sci. 2006;4:1-10. [65] Tomar AK, Sooch BS, Singh S, Yadav S. Differential proteomics of human seminal plasma: A potential target for searching male infertility marker proteins. Proteom Clin ApplProteomics Clinical Applications. 2012;6:147-51.

[66] Fung KYC, Glode LM, Green S, Duncan MW. A comprehensive characterization of the peptide and protein constituents of human seminal fluid. Prostate. 2004;61:171-81.

[67] Findlay GD, Yi XH, MacCoss MJ, Swanson WJ. Proteomics reveals novel

Drosophila seminal fluid proteins transferred at mating. PLOS Biology. 2008;6:1417-26. [68] Sirot LK, Hardstone MC, Helinski MEH, Ribeiro JMC, Kimura M, Deewatthanawong $\mathrm{P}$, et al. Towards a semen proteome of the dengue vector mosquito: Protein identification and potential functions. Plos Neglect Trop Dis. 2011;5.

[69] Georgiou SA, Sostaric E, Wong CH, Snijders APL, Wright PC, Moore HD, et al. Gametes Alter the Oviductal Secretory Proteome Mol Cell Proteomics. 2005;4:1785-96. [70] Wasbrough ER, Dorus S, Hester S, Howard-Murkin J, Lilley K, Wilkin E, et al. The Drosophila melanogaster sperm proteome-II (DmSP-II). J Proteomics. 2010;73:2171-85. [71] Wigby S, Sirot LK, Linklater JR, Buehner N, Calboli FCF, Bretman A, et al. Seminal fluid protein allocation and male reproductive success. Curr Biol. 2009;19:7517.

[72] Kubli E. Sex-peptides: Seminal peptides of the Drosophila male. CMLS Cell Mol Life Sci. 2003;60:1689-704.

[73] Yapici N, Kim YJ, Ribeiro C, Dickson BJ. A receptor that mediates the post-mating switch in Drosophila reproductive behaviour. Nature. 2008;451:33-U1.

[74] Ram KR, Wolfner MF. Seminal influences: Drosophila Acps and the molecular interplay between males and females during reproduction. Integr Comp Biol. 2007;47:427-45.

[75] Ram KR, Wolfner MF. Sustained post-mating response in Drosophila melanogaster requires multiple seminal fluid proteins. PLoS Genet. 2007;3:2428-38.

[76] Dean MD, Clark NL, Findlay GD, Karn RC, Yi XH, Swanson WJ, et al. Proteomics and comparative genomic investigations reveal heterogeneity in evolutionary rate of male reproductive proteins in mice (Mus domesticus). Mol Biol Evol. 2009;26:1733-43.

[77] Ramm SA, McDonald L, Hurst JL, Beynon RJ, Stockley P. Comparative proteomics reveals evidence for evolutionary diversification of rodent seminal fluid and its functional significance in sperm competition. Mol Biol Evol. 2009;26:189-98.

[78] Marshall JL, Huestis DL, Garcia C, Hiromasa Y, Wheeler S, Noh S, et al.

Comparative proteomics uncovers the signature of natural selection acting on the ejaculate proteomes of two cricket species isolated by postmating, prezygotic phenotypes. Mol Biol Evol. 2011;28:423-35.

[79] Boomsma JJ, Baer B, Heinze J. The evolution of male traits in social insects. Annual Review of Entomology. 2005;50:395-420.

[80] Baer B. Sexual selection in Apis bees. Apidologie. 2005;36:187-200.

[81] Baer B. The copulation biology of ants (Hymenoptera: Formicidae). Myrmecol News. 2011;14:55-68. 
713

714

715

716

717

718

719

720

721

722

723

724

725

726

727

728

729

730

731

732

733

734

735

736

737

738

739

740

741

742

743

744

745

746

747

748

749

750

751

752

753

754

755

756

757

758

[82] Baer B. Sexual Selection in Social Insects. In: Shuker D, Simmons LW, editors. The Evolution of Insect Mating Systems. Oxford: Oxford University Press; 2014. p. 261-74. [83] Hamilton WD. The genetical evolution of social behavior I \& II. J Theor Biol. 1964;7:(I): 1-16; (II): 7-32.

[84] Trivers RL, Hare H. Hapoldiploidy and the evolution of the social insects. Science. 1976;191:249-63.

[85] Hunter FM, Birkhead TR. Sperm viability and sperm competition in insects. Curr Biol. 2002;12:121-3.

[86] Weber NA. Gardening ants: The attines. Philadelphia: The American Philosophical Society; 1972.

[87] Keller L, Genoud M. Extraordinary lifespans in ants: a test of evolutionary theories of ageing. Nature. 1997;389:958-60.

[88] Baer B. Female Choice in Social Insects. In: Peretti A, Aisenberg A, editors. Cryptic Female Choice in Arthropods: Patterns, Mechanisms and Prospects. Stuttgart: Springer; 2015. p. 461-77.

[89] Avila FW, Sirot LK, LaFlamme BA, Rubinstein CD, Wolfner MF. Insect seminal fluid proteins: Identification and function. Annual Review of Entomology. 2011;56:2140.

[90] Chapman T. Seminal fluid-mediated fitness traits in Drosophila. Heredity. 2001;87:511-21.

[91] Chapman T. The soup in my fly: Evolution, form and function of seminal fluid proteins. PLOS Biology. 2008;6:1379-82.

[92] Poiani A. Complexity of seminal fluid: a review. Behav Ecol Sociobiol. 2006;60:289-310.

[93] Polak M, Wolf Larry L, Starmer William T, Barker JSF. Function of the mating plug in Drosophila hibisci Bock. Behav Ecol Sociobiol. 2001;49:196-205.

[94] Baer B, Maile R, Schmid-Hempel P, Morgan ED, Jones GR. Chemistry of a mating plug in bumblebees. J Chem Ecol. 2000;26:1869-75.

[95] Mikheyev AS. Evidence for mating plugs in the fire ant Solenopsis invicta. Insectes Sociaux. 2003;50:401-2.

[96] Mikheyev AS. Male accessory gland size and the evolutionary transition from single to multiple mating in the fungus-gardening ants. Journal of Insect Science. 2004;4:1-5. [97] Baer B, Morgan ED, Schmid-Hempel P. A non-specific fatty acid within the bumblebee mating plug prevents females from remating. Proc Natl Acad Sci USA. 2001;98:3926-8.

[98] Sauter A, Brown MJF, Baer B, Schmid-Hempel P. Males of social insects can prevent queens from multiple mating. Proc R Soc B. 2001;268:1449-54.

[99] Baer B, Heazlewood JL, Taylor NL, Eubel H, Millar AH. The seminal fluid proteome of the honeybee Apis mellifera. Proteomics. 2009;9:2085-97.

[100] den Boer SPA, Boomsma JJ, Baer B. Honey bee males and queens use glandular secretions to enhance sperm viability before and after storage. J Insect Physiol. 2009;55:538-43.

[101] King M, Eubel H, Millar AH, Baer B. Proteins within the seminal fluid are crucial to keep sperm viable in the honeybee Apis mellifera. J Insect Physiol. 2011;57:409-14. [102] Peng Y, Imhoof-Baer B, Millar AH, Baer B. Consequences of Nosema apis infection for male honey bees and their fertility. Sci Rep. 2015;5:1-5. 
[103] Roberts K, Evison S, Baer B, Hughes WOH. The cost of promiscuity: sexual transmission of Nosema microsporidian parasites in polyandrous honey bees. Sci Rep.

$7612015 ; 5: 1-7$.

762 [104] Birkhead TR, Moller AP. Sperm competition and sexual selection. New York:

763 Academic Press; 1998.

764 [105] Eberhard WG, Cordero C. Sexual conflict and female choice. Trends Ecol Evol.

765 2003;18:438-9.

766 [106] den Boer SPA, Baer B, Boomsma JJ. Seminal fluid mediates ejaculate competition

767 in social insects. Science. 2010;327:1506-9.

768 [107] Poland V, Eubel H, King M, Solheim C, Millar AH, Baer B. Stored sperm differs

769 from ejaculated sperm by proteome alterations associated with energy metabolism in the

770 honeybee Apis mellifera. Mol Ecol. 2011;20:2643-54.

771 [108] Zareie R, Eubel H, Millar AH, Baer B. Long term survival of high quality sperm:

772 Insights into the sperm proteome of the honeybee Apis mellifera. J Proteome Res.

773 2013; 12:5180-8.

774 [109] Paynter E. Cellular energetics of long-term survival and storage in honeybee sperm.

775 Perth: The University of Western Australia; 2015.

776 [110] Baer B, Eubel H, Taylor NL, O'Toole N, Millar AH. Insights into female sperm storage from the spermathecal fluid proteome of the honeybee Apis mellifera. Genome Biology. 2009;10:R 67.

[111] Baer B, Zareie R, Paynter E, Poland V, Millar AH. Seminal fluid proteins differ in abundance between genetic lineages of honeybees. J Proteomics. 2012;75:5646-53. [112] Graves PR, Haystead TAJ. Molecular biologist's guide to proteomics. Microbiol Mol Biol Rev. 2002;66:39-63.

[113] Ram KR, Sirot LK, Wolfner MF. Predicted seminal astacin-like protease is required for processing of reproductive proteins in Drosophila melanogaster. Proc Natl Acad Sci U S A. 2006;103:18674-9. [114] Wyatt TD. Proteins and peptides as pheromone signals and chemical signatures. Anim Behav. 2014;97:273-80.

[115] Georgiou AS, Snijders APL, Sostaric E, Aflatoonian R, Vazquez JL, Vazquez JM, et al. Modulation of the oviductal environment by gametes. J Proteome Res. 2007;6:4656-66. [116] Wilburn DB, Bowen KE, Doty KA, Arumugam S, Lane AN, Feldhoff PW, et al. Structural insights into the evolution of a sexy protein: Novel topology and restricted backbone flexibility in a hypervariable pheromone from the Red-Legged Salamander, Plethodon shermani. PLoS One. 2014;9. 
Table 1: A focus on proteins as drivers of ecological and evolutionary processes offer

800 researchers from various fields novel opportunities to explain biological phenomena such

801 as rapid evolutionary and adaptive changes, especially in cases where the traditional

802 focus on DNA mutation followed by natural selection provide unsatisfying proximate

803 explanations for observed phenotypes. Furthermore, molecular biologists focusing on the

804 use of -omics approaches to understand variation in their datasets can use evolutionary

805 and ecological explanations in hypothesis building for followup experiments..

\begin{tabular}{|c|c|c|c|}
\hline & Areas of Interest & $\begin{array}{l}\text { Protein/Proteome } \\
\text { Feature }\end{array}$ & Literature \\
\hline \multirow{5}{*}{$\begin{array}{c}\text { Evolution } \\
\text { (Proteome changes } \\
\text { over generations) }\end{array}$} & Evolution of traits & $\begin{array}{l}\text { Proteins modify } \\
\text { genomic information } \\
\text { flow through DNA } \\
\text { modifications and } \\
\text { structure }\end{array}$ & $\begin{array}{l}{[50,55,} \\
56]\end{array}$ \\
\hline & Heritability & $\begin{array}{l}\text { Proteins are all genome } \\
\text { derived but can also act } \\
\text { as non-genomic } \\
\text { components of } \\
\text { transgenerational } \\
\text { inheritance }\end{array}$ & $\begin{array}{l}{[25-27,39,} \\
57]\end{array}$ \\
\hline & Natural Selection & $\begin{array}{l}\text { Proteins are the } \\
\text { biologically active } \\
\text { "agents" and proximate } \\
\text { drivers of fitness }\end{array}$ & $\begin{array}{l}{[40,49} \\
100,101 \\
108,113]\end{array}$ \\
\hline & Natural Variation & $\begin{array}{l}\text { Proteomes are } \\
\text { substantially more } \\
\text { diverse than the } \\
\text { underlying genomes. }\end{array}$ & {$[23,24]$} \\
\hline & Speciation & $\begin{array}{l}\text { Proteins can be drivers } \\
\text { of reproductive } \\
\text { isolation }\end{array}$ & [114] \\
\hline \multirow{2}{*}{$\begin{array}{c}\text { Ecology } \\
\text { (Proteome-Proteome } \\
\text { and Proteome - } \\
\text { Environment } \\
\text { interactions }\end{array}$} & Adaptation & $\begin{array}{l}\text { Proteins are drivers of } \\
\text { ecological adaptation, } \\
\text { and spread through } \\
\text { introgression and } \\
\text { horizontal gene transfer }\end{array}$ & $\begin{array}{l}{[4,5,7,} \\
43]\end{array}$ \\
\hline & $\begin{array}{l}\text { Genotype } \mathrm{x} \\
\text { Environment } \\
\text { Interactions } \\
\end{array}$ & $\begin{array}{l}\text { Protein networks are } \\
\text { susceptible to } \\
\text { environmental stimuli }\end{array}$ & {$[107]$} \\
\hline
\end{tabular}




\begin{tabular}{|l|l|l|l|}
\hline & $\begin{array}{l}\text { and can transfer such } \\
\text { information to influence } \\
\text { the transciptome and } \\
\text { the epigenome }\end{array}$ & | \\
\cline { 2 - 4 } & $\begin{array}{l}\text { Host-Parasite } \\
\text { Interactions } \\
\text { a driver of virulence } \\
\text { and immunity }\end{array}$ & {$[8,40,47]$} \\
\cline { 2 - 4 } & $\begin{array}{l}\text { Protein networks and } \\
\text { Phatrixes are highly } \\
\text { variable and change due } \\
\text { to genomic and } \\
\text { ecological factors }\end{array}$ & {$[23,49]$} \\
& {$[54,115]$} & $\begin{array}{l}\text { Proteins can be } \\
\text { molecular drivers of } \\
\text { conflicts over paternity }\end{array}$ & {$[71-73$,} \\
\cline { 2 - 4 } & Sexual Selection & $116]$ \\
\hline
\end{tabular}

806

807

808 


\section{Figure Legends}

810

811 Figure 1

812 The Central Dogma coupled to other regulatory steps and mechanisms of

813 environment-dependent variation that influence the proteome. The central blue box

814 presents the primary flow of molecular information as found in all living organisms,

815 through which DNA encodes for genes that are transcribed into RNA which in many

816 cases are translated into proteins. The latter are principally responsible for the expression

817 of a specific phenotype. Research over the past decades has now shown that this central

818 protein building system is augmented by a range of more dynamic protein and proteome-

819 modifying factors which are influenced by environmental factors. This presentation

820 highlights the role of proteins and their variation as additional drivers of physiological

821 processes and their evolution rather than simply as end points of molecular information

822 flow. 